\title{
INTERDISCIPLINARY STUDY FOR KNOWLEDGE AND DATING OF THE SAN FRANCESCO CONVENT IN STAMPACE, CAGLIARI - ITALY (XIII-XXI CENTURY)
}

\author{
C. Giannattasio ${ }^{\mathrm{a}}$, S.M. Grillo ${ }^{\mathrm{a}}$, G. Vacca ${ }^{\mathrm{a}}$ \\ ${ }^{a}$ DICAAR, Department of Civil and Environmental Engineering and Architecture \\ University of Cagliari \\ P.zza D’Armi - 09123 Cagliari, Italy \\ vaccag@unica.it
}

KEYWORDS: Chronological methods, interdisciplinary approach, Laser Scanner, survey, geomaterial characterization.

\begin{abstract}
:
The Franciscan monastery, situated in the historic center of Cagliari (Sardinia), was founded in the thirteenth century, and transformed during the later centuries, up to the present day. The complexity of the case and the lack of objective data about its history has led us to carry out an interdisciplinary inquiry, in order to achieve a better knowledge of the building, preliminary for the drafting of a restoration project that respects all the signs that the time left. Starting from a deep examination of the indirect sources, turned out to be incomplete, the investigation continued with the execution of a survey with laser scanner and with the characterization of materials and related diseases of degradation.

For the laser scanner survey we used a Faro Focus 3D, versatile and lightweight instrument that allows to perform scans with high speed point acquisition and high accuracy. For data elaboration we used the JRC 3D Reconstructor Software by the Gexcel srl.

The characterization of the materials was performed on a reasoned sampling of natural and artificial materials, referring to masonry, interstitial mortars and plasters, carried out at strategic points, representative of the various phases of the construction. The samples were studied through mineralogical-petrographic methods with instrumental techniques for the analysis of component materials (OM, X-Ray diffraction).

The data obtained, crossed with the results of the reconstruction of historical maps, of the examination of masonry techniques and of the analysis of pattern elements (arches, vaults, decorative elements), have facilitated stratigraphic analysis and helped to advance chronological reasoned hypothesis referring to the building. Besides, an interdisciplinary approach for the study of cultural heritage is very important to define a proper restoration and conservation intervention.
\end{abstract}

\section{INTRODUCTION}

This paper presents the results of a study performed by a team of researchers of the Department of Civil and Environmental Engineering and Architecture (DICAAR) of the University of Cagliari about the religious complex titled to St. Francis, located in the historical quarter of Stampace in Cagliari. Dating back to the XIII century, in the course of the centuries, it was object of various transformations, alterations and collapses which modified both its original size and structure and the type of materials used. Also, the documentation about the interventions occurred since the origin of the building is no longer available in the historical archives. Finally, the multiple interventions operated on the religious complex with different techniques, workers and materials complicate any attempt to read its history.

In this situation, preparing a study in support to a restoration project for conservation and/or utilization purposes is very difficult. It was thus essential to adopt an interdisciplinary approach that could supply information on the dimensional, architectural and material aspects of the building, allowing a complete reconstruction of the interventions in the time and enabling the choice of a future restoration project proposal.

The work stages in the protocol used for the study of the St. Francis complex were the following ones:

- historical-architectural study of the complex;

- 3D laser scanner survey;

- preparation of the graphic outputs;

- characterization of the materials;
- materials and degradation analysis;

- stratigraphy and chronology of the architecture.

From these multidisciplinary work stages, which involved restoration experts, surveyors, petrographists, we obtained a complete knowledge of the building. The systematization of all collected data was also a fundamental support for the stratigraphic analysis of the raised parts, on which a dating hypothesis for the structure has been carried out, as a fundamental premise for the definition of a conservative restoration project.

\section{THE FRANCISCAN CONVENT}

\subsection{Historical notes}

The St. Francis architectural complex was formed originally by a church and a series of buildings used as a convent, surrounding a large cloister, whose main axes are oriented in the north-east to south-west direction (Figure 1).

Because of a succession of events, it is now in an advanced state of decay, only keeping the ground floors of the eastern, southern and western parts defining the cloister's area, in addition to the building on the west side, which originally housed the refectory. The northern part is the only one to has kept its upper level, although completely embedded in the newer buildings built in the late $19^{\text {th }}$ century, consequently to the demolition of the church and the urban renewal of the area. The southern part of the cloister is also very compromised, 
having been cut in order to open a new street in the middle $20^{\text {th }}$ century (Figure 2).

Regarding the foundation date of the building, the existing archive documentation does not provide certain information. It is anyway known that the Franciscans were present in Sardinia since 1229 (AA. VV. 1991).

The church, demolished in the late $19^{\text {th }}$ century, might have been built at the end of the $13^{\text {th }}$ century (Coroneo, 1993; Delogu, 1953). During the $15^{\text {th }}$ and $16^{\text {th }}$ centuries, several side chapels in gothic-Catalan style were adjoined to the original main body, along its longitudinal walls.

Like in the church's case, the date of construction of the convent is not known. Some researchers ascribe it to the end of the $13^{\text {th }}$ century, others to the period between the $13^{\text {th }}$ and $16^{\text {th }}$ centuries; in a phase certainly following the Counterreformation, several new side chapels were built, causing the doubling of the eastern part facing the cloister.

From the $19^{\text {th }}$ century on, the complex faced a sharp decline, especially following the laws on the abolition of the religious orders, causing in 1861 the definitive closing of the structure, which was confiscated into the state properties. It was thus used as a station of the Carabinieri corps, while the church was still in use for some years; it was demolished, due to its precarious structural condition, in the late 1870s.

The buildings facing the cloister were seriously damaged in the bombings of 1943, losing their respective upper levels. Later in 1949, as formerly recounted, the southern side was cut down.

The main contributions to the general state of decay were the insertion of inappropriate functions and the abandonment of entire parts of the structure, irreversibly compromising this monumental heritage and its high historical, artistic and cultural value.

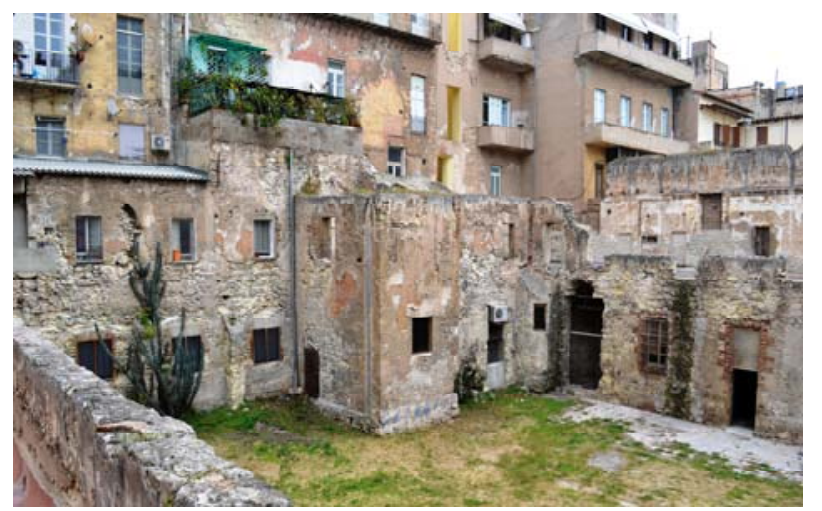

Figure 1: The St. Francis complex in its present state, as seen from the south-west direction

\subsection{Spatial, dimensional and formal aspects}

In general, the buildings facing the cloisters show a floorplan articulated in square modules, with crossed vaults carried by finely decorated pillars and capitals, with some variants, caused by the subsequent stratifications which clearly compromised the original homogeneity of the architectural work. The spatial system was characterized by a complete continuity between the modules, later lost in order to create, for purely functional purposes, separate rooms. This also entailed the closing of the colonnade towards the cloister, by building exterior walls of different heights. In order to appreciate the dimensional and stylistic aspects, of great help in dating the structures, the degree of precision obtained in the survey of the building was of fundamental importance. In detail, the buildings that delimitate the cloister on north, south and west sides - the latter connected with the former refectory - have seven modules of dimensions $3.21 \mathrm{~m} \times 3.21 \mathrm{~m}$, and are characterized by a very simple decoration, with arches between the spans, supported by corbels, moldings and bases, and crossed vaults with pendulous. The rectangular modules exhibit large arches on corbels.

The east side presents numerous anomalies in comparison with the other sides. It consists of a double row of crossed vaults, with different dimensional and formal characteristics. Initially, its plan was based on a single order of six modules $3.66 \mathrm{~m} \mathrm{x}$ $3.66 \mathrm{~m}$, i.e. the outer. The inner one, built at a later stage to accommodate chapels, is composed of different modules, 3.13 $\mathrm{m} \times 3.13 \mathrm{~m}$. The two parts communicate through a series of arches, of different typologies.

The knowledge of the building was greatly helped by the systematic analysis of the system of vaults and arches, supported in turn by the drawing of synthetic graphical drafts, particularly useful in making formal and stylistic assessments (Figure 3). Also important was the mapping of the wall types and their representation, supporting on the basis of chronotypological assessments the dating of structures, in some cases overturning the previous theories, mainly proposed by arts historians and medievalist archeologists, which were centered on stylistic considerations, but ignored completely the modern phases which seriously affected the edifice.

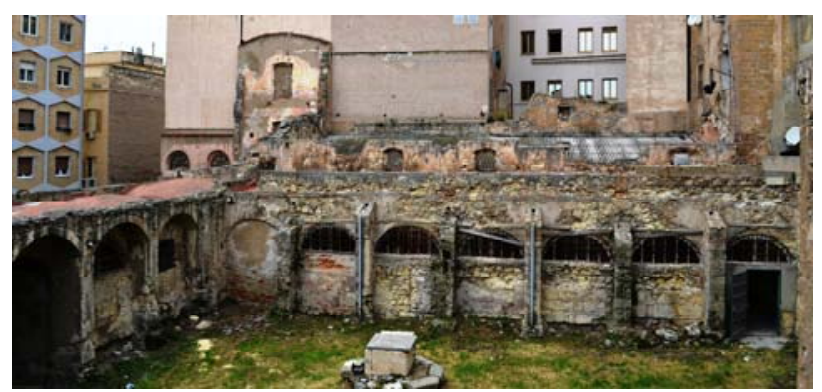

Figure 2: The buildings facing the cloister as seen from the north-east

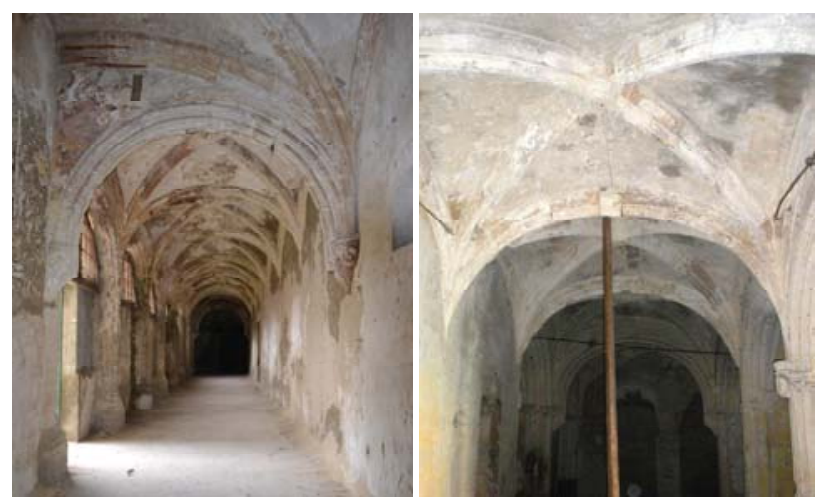

Figure 3: Detail of the western side and interior of the eastern one facing the cloister

\section{THE LASER SCANNER SURVEY}

When beginning the study of a cultural heritage site of which no historical and drawing documentation is available, the first step is to perform a metric survey with an accuracy that is adequate for the study. In the case of the St. Francis cloister, for which there was no reliable draft, and considering the complex architectural structure with its multiple vaults, we choose to perform a 3D survey with a terrestrial laser scanner (TLS). A TLS survey produces a high density point clouds, providing for each point $\mathrm{x}, \mathrm{y}, \mathrm{z}$ coordinates in the instrument's reference 
system and the reflectance (indicative of the physical characteristics of the surface).

Through the acquisition of digital images, the survey was completed with the RGB data that allowed to integrate the analysis of the structure with further information regarding, for example, its state of decay. A laser scanner survey enabled the architectural heritage experts to inspect the actual and complete geometry of the building and to examine its construction techniques, simplifying the study of the architectural details which were difficult to obtain with traditional survey (Kersten et al., 2005).

The survey of the St. Francis cloister was performed using the Faro Focus 3D TLS. It is a compact scanner with $0.6 \mathrm{~m}$ to 120 $\mathrm{m}$ range of scanning distance, a linear distance error of $\pm 2 \mathrm{~mm}$ (at distances between 10 and $25 \mathrm{~m}$ ), and a noise (intended as standard deviation of values from the best-fit plane) variable between $0.6 \mathrm{~mm}$ (at $10 \mathrm{~m}$ distance, with $90 \%$ reflectivity) and $2.5 \mathrm{~mm}$ (at $25 \mathrm{~m}, 10 \%$ reflectivity). The field of view is $305^{\circ}$ in vertical and $360^{\circ}$ in horizontal. The scan rate is of 976000 dot/sec. The Focus 3D integrates a color digital camera with a resolution of 70 megapixel.

The choice of using the Focus 3D was due to the performance of this TLS. The limited weight and size, the speed of the point acquisition and user friendliness makes it a versatile TLS that can also be used by non-experts in geomatic surveys.

The stages involved in TLS survey and the restitution of the graphic output were:

- scans planning;

- scan acquisition;

- GPS survey for georeferencing the point clouds;

- data processing;

- automatic extraction of horizontal and vertical sections;

- creation of orthophoto;

- restitution and editing of the graphic outputs.

In order to correctly design the survey, we started from the accuracy needed for the graphic works to be used in the study of the cloister. In particular, 1:100 scale restitutions were required for the horizontal sections, vertical sections and elevations, while for some architectural details the required scale was 1:20.

For the definition of the point density, we relied on the experience and specifications of the English Heritage (Bryan P. et al. 2009). The Table 1 reports the specifications corresponding to the required representation scales.

\begin{tabular}{|l|l|l|}
\hline Scale & Point Density & Precision \\
\hline $1: 20$ & $2.5 \mathrm{~mm}$ & $+/-2.5 \mathrm{~mm}$ \\
\hline $1: 100$ & $15.0 \mathrm{~mm}$ & $+/-15.0 \mathrm{~mm}$ \\
\hline
\end{tabular}

Tab. 1: Specifications for the density of points in function of the required precision (Bryan P. et al. 2009) .

Even so, because of the complexity of the cloister and the abundance of architectural details (columns, vaults), in order to obtain its complete survey without shadowed or hidden zones we performed 91 scans, both indoor and outdoor, with an average resolution of $6 \mathrm{~mm}$, plus a series of scans with $2 \mathrm{~mm}$ resolution for architectural details.

The scans were performed both on the ground floor (indoor and courtyard) and on the roof, in order to obtain a complete reconstruction of the roofing and of all elements on the ground level of the cloister.

The Figure 4 shows the positions of the outdoor scans performed both on the ground level and on the floor.
During the scans, a number of signals were positioned in the inner and outer court (Figures 5 and 6), to be used in the georeferencing phase of point clouds. The coordinates of the signals were surveyed with a RTK (real-time kinematic) GPS survey in the ETRF2000 reference system (with geoid heights). The differential corrections were supplied by the SARNET permanent station network (www.sarnet.it).

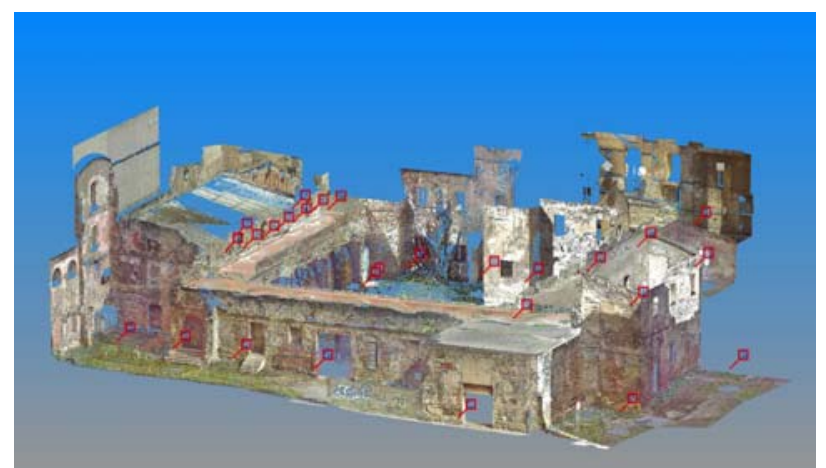

Figure 4: Positions of the outdoor scans in the survey of the St. Francis cloister
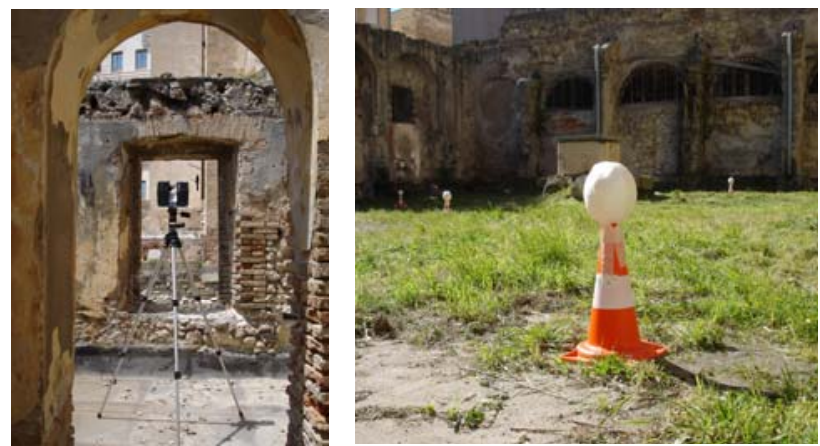

Figures 5 and 6: Outdoor scan. Signals for the georeferencing of the point clouds

The management and processing of the point clouds was performed in the JRC Reconstructor 2 (v. 2.8.02.247) by Gexcel srl. The Reconstructor 2 software allowed to perform all the processing of the point clouds up to the definition of the 3D model of the surveyed heritage (Deidda et al. 2012).

The scans were first pre-processed and then, by using exclusively natural features (at least five for each pair of scans), pre-aligned and finally aligned, obtaining residuals below one centimeter. The point cloud so obtained was then georeferenced in the ETRF2000 reference system (with geoid heights) by using the signals placed in the inner and outer courtyards.

\subsection{Graphic outputs}

From the 3D model of the cloister, by using the JRC Reconstructor software, we extracted the following graphic products:

- horizontal sections at various heights from the floor for the roof floor;

- vertical sections in various places of the structure;

- orthophoto of architectural elements (walls, outer prospects, vaults, friezes) for the restitution of the corresponding elements with a GSD (ground sampling distance of $2 \mathrm{~cm}$ ).

From the sections and the orthophoto, with a long editing work, we restituted all the graphic outputs (horizontal sections and vertical sections) describing the cloister. 
The Figure 7 displays an example of section and orthophoto automatically extracted from the software and the same section after manual editing.
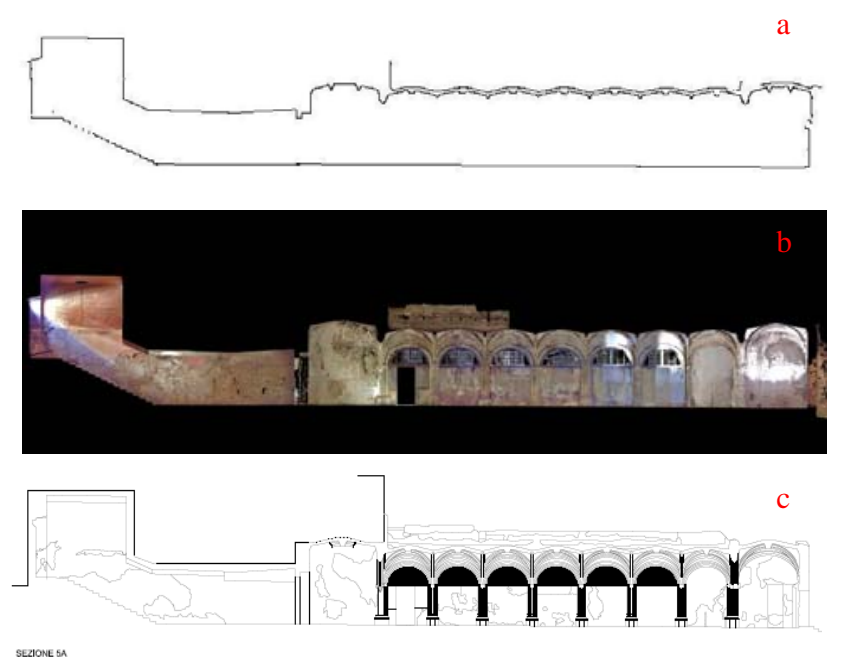

Figure 7: a) A vertical section generated by the software; b) an orthophoto generated by the software; c) a vertical section restituted by an operator with the support of the orthophoto

\section{CHARACTERIZATION OF THE STONE MATERIALS}

The restoration project of the St. Francis cloister also involved a detailed study of natural and artificial stone materials used in the building.

The cloister is built with carbonate rocks of the Oligo-Miocenic series, surfacing in the hills on which Cagliari is built, and commonly known as "pietra cantone", "tramezzario" and "pietra forte". The stratigraphic sequence of this area from bottom to top comprises the "pietra cantone", i.e. a limestone, sometimes argillaceous, with color varying between cream and yellow, with abundant remains of macrofauna (bryozoa, lamellibranchia, etc.) and microfauna (globigerina, globorotalia, etc.), very soft, hygroscopic, easily attacked by external forces. Its physical-mechanical properties limited its use to walls refined with plaster and architectural ornaments; the "pietra forte", an organogenic reef limestone in facies of bioherma and biostroma, with copious organogenic remains of mollusca, algae and foraminifera, very compact, generally white in color. Utilized from the Roman times to the early sixties of the $20^{\text {th }}$ century for its excellent physical and mechanical properties, it was used in the visible works and to build portals, frames, columns, pilasters, etc. The materials forming the load-bearing structure of the cloister are shown in the Figures 8 and 9.

With the help of the orthophoto extracted from the laser scanner survey it has been possible to provide an analytical distribution of the material types through a graphical restitution of the survey (Figure 8 e). As evidenced by the maps, the cloister is built almost entirely with squared ashlar blocks and rubble masonry in "pietra cantone" (Figure 8 a-b-c) with rare blocks of "pietra forte" (Figure $8 \mathrm{~d}$ ).

The examined structure suffers from serious degradation. Weathering is manifested in the walls with the formation of black crusts, efflorescences, sub-efflorescences, alveolizations, decohesions, etc., while anthropic degradation is manifested in detachment and decohesion phenomena of plasters and mortars and it is mostly due to repeated interventions performed over the years with improper materials, not compatible with the historical ones (Siegesmund, Snethlage, 2008).
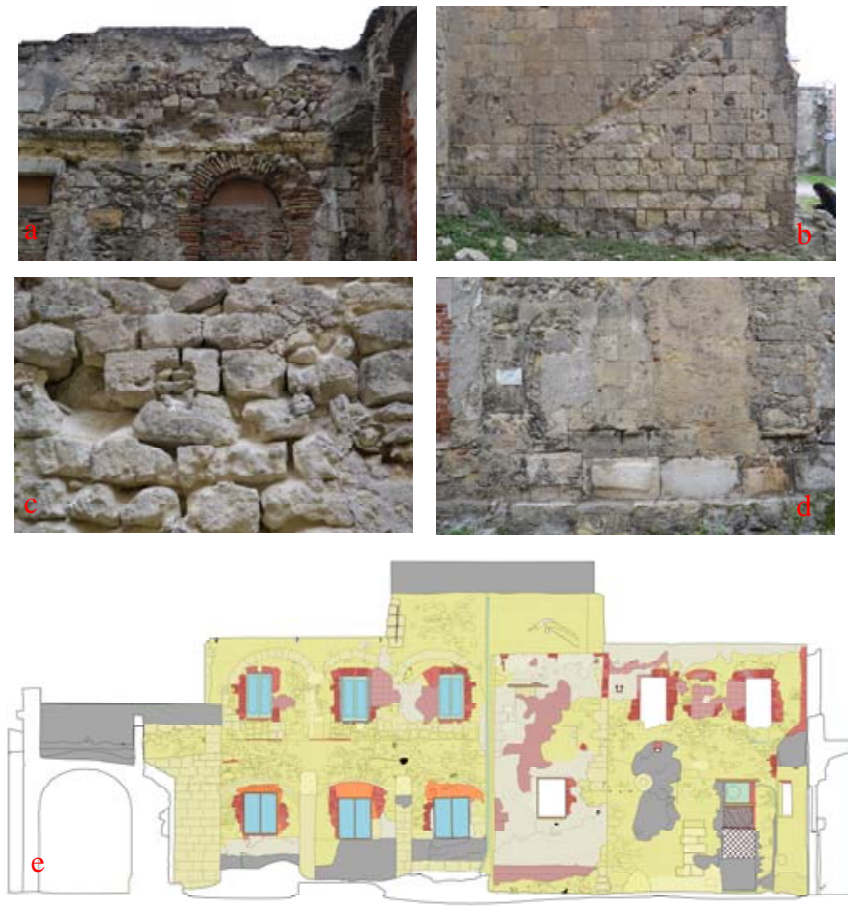

Figure 8: Stone materials used in the building: a), b), c) walls built in "pietra cantone" ashlar and rubble; d) "pietra forte"

bossed blocks; e) the north facade with the mapping of materials (yellow "pietra cantone”, grey "plaster”, red "solid brick”, orange "hollow brick”, pink "painting”)

The mineral-petrographical diagnostic has interested mostly the characterization of the artificial stone materials, these being the main cause of the structural instability, but also the detailed definition of the various forms of weathering which affected the walls (Pecchioni, Fratini, Cantisani, 2008).

On the mortars and plasters we also performed a reasoned sampling, using a lancet for the non-coherent materials and a micro-scalpel for the compact ones, according with the Nor.Ma.L. 3/88 guidelines. The number of samples, sufficient for representing all the different material types, is the result of a preliminary analytical investigation performed in various points of the structure. We then sampled the different types of plastering and mortars, put in place at different times and with different techniques.

The plasters, with colors varying from cream to dark gray, are extremely deteriorated, showing complete lack of cohesion both with the underlying wall and with the older layers of plaster, which in some cases keep the old paint with colors varying from gray to ochre tones. The Figure 9 (a-b) shows the stratigraphy of the various layers of plaster, where is recognizable an older, millimeter-thick layer of white plaster in direct contact with the wall structure (particular in b), and the layers (in a 2-3) applied in later times, affected by advanced states of chalking and decohesion and identifiable from the different color and thickness (which can reach several centimeters). As we can see in the figure $9 \mathrm{c}$-d, several layers of plaster are displayed, still showing old paints of various colors. The binder/aggregate composition was studied through optical microscopy with transmitted light and X-ray diffraction (Fiorino et al, 2012). This is very important, in a possible project phase, to choose mortars and plasters compatibles by a 
chemical and physical point of view with those used for the original ones.

With regards to the composition, the most recent layers of plaster, they generally show a binder with hydraulic properties and a coarser aggregate with respects to the older layers, which are always based on lime and characterized by aggregates rarely exceeding $2 \mathrm{~mm}$ in size.

The cream-colored mortars are generally very degradation, with low cohesion and similar to the oldest white plaster (Figure 9c). They are limes with carbonatic binder and quartz-feldspar aggregate, with copious carbonatic fragments and fossil remains.

The study of materials and of its conservation has been very important for the knowledge of the building, that is fundamental for the definition of intervention lines. Contrariwise, because of the absence of systematic chrono-typological studies concerning the regional context, the materials analysis did not provide useful information for dating the structure.
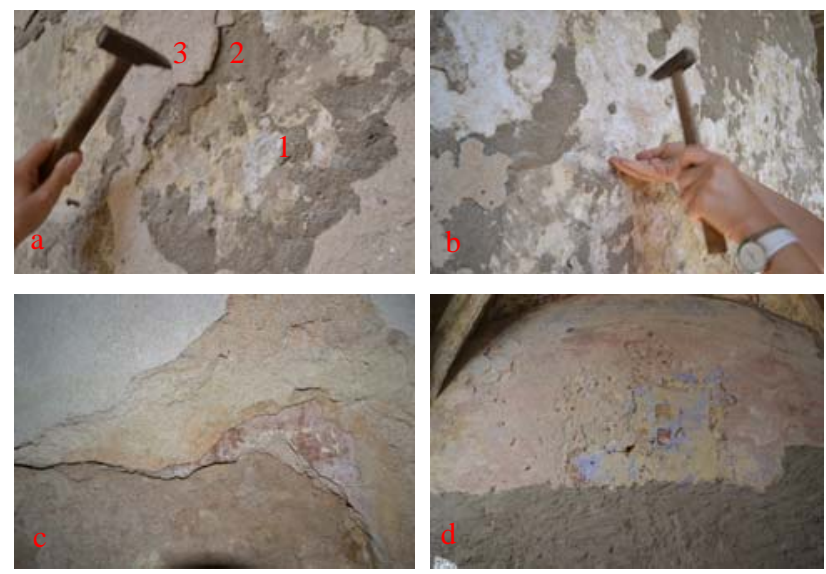

Figure 9: a) Sampling the different types of plaster found in the structure; three layers of plaster are recognizable (1 white, innermost, on wall; 2 dark gray, intermediate; 3 light gray, outer); b) detail of the oldest plaster layer; c-d) consecutive

layers of plaster, up to $1 \mathrm{~cm}$ thick, placed on older layers, often still carrying the original paint

\section{STRATIGRAPHIC ANALYSIS AND CHRONOLOGICAL DEFINITION OF THE STRUCTURES}

As anticipated, the study of the complex was based on the direct analysis of the places, supported by the historical information, the existing cartographic, iconographic and photographic documentation, the analysis of decorative elements, the study of the building's stratigraphic units and of the relationship between its parts.

In detail, the stratigraphic method was divided into three main phases (Figure 10). The first-one consisted in the identification of the stratigraphic units, as follows:

- masonry stratigraphic units (msu);

- surface stratigraphic units (ssu);

- negative stratigraphic units (nsu).

The second phase was centered on the definition of the connections between the various stratigraphic units, both direct and indirect, in order to establish diachronic or synchronic relationships between the parts. Subsequently we built a relative chronology between the units, with the support of the Harris diagram we drew, i.e. of a stratigraphical diagram very useful to relate the different building phases. Lacking archival sources, it was not possible to obtain an absolute chronology, but on the basis of the relative one, we were able to associate a temporal interval to each identified phase. In detail, following this investigation, it has been possible to hypothesize that the complex was built in subsequent phases, some of them very close to each other (Figure 11).

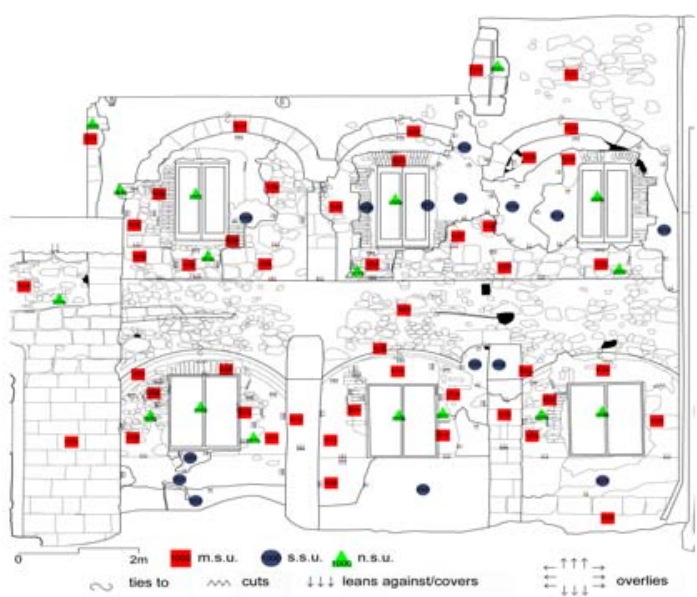

Figure 10: Detail of the north facade, stratigraphic analysis of the structures

To the first phase, around the $15^{\text {th }}-16^{\text {th }}$ century, can be ascribed the external module of the eastern side of the cloister, and in particular the six quadrangular spans with crossed vaults and the rectangular space to the north and to the south. This hypothesis is supported by the fact that the spatial and stylistic features of the complex are similar to those found in the Dominican convent situated in Cagliari, in the Villanova historical quarter, dated, on the basis of archive documents yet unpublished, at the same period. Also, the space used as refectory seems to belong to this time, as confirmed by the wall typologies identified in its longer sides. In a second phase, corresponding to the middle $16^{\text {th }}$ century, the cloister's space would be completed with the building of the northern, western and southern sides, including the connecting corner spaces. The fact that the cloister was built in different moments is confirmed by the use of modules of various sizes. The proposed dating seems to find a confirmation, first of all, in the presence of a homogeneous wall typology, found in the same geographical area in structures of that age. Further transformations interested the refectory, where the partition walls transverse to the older walls, in the east-west direction, seem to derive from a will to reduce and rationalize the spaces.

During a third phase, between the end of the $16^{\text {th }}$ and the first half of the $17^{\text {th }}$ century, a deep transformation of the original configuration seems to have taken place. In effect, following the precepts of the Council of Trent, chapels would be built next to the older eastern side, doubling it towards the west, and closing permanently the arches on the cloister. According to some archive documents, two more chapels would have been built at the same time on the opposing side, to the east, together with the new building to the south. Also, next to the northern, western and southern sides, buttresses were built in order to reinforce the existing load-bearing structures as well as, for the southern side, to support the raising of a second floor (which was also added to the northern and eastern sides).

The two chapels overhanging from the northern front, and shortly later the edifice at the center of the same side, seem to have been built in a fourth and fifth phase, very close to each other, which can be placed in a period included between the $17^{\text {th }}$ and $18^{\text {th }}$ 
centuries but earlier than 1736, date of one of the historical maps we studied. Attesting to that is the lateral prospect of the same building, which leans against one of the aforementioned buttresses, proving it was built in a later phase.

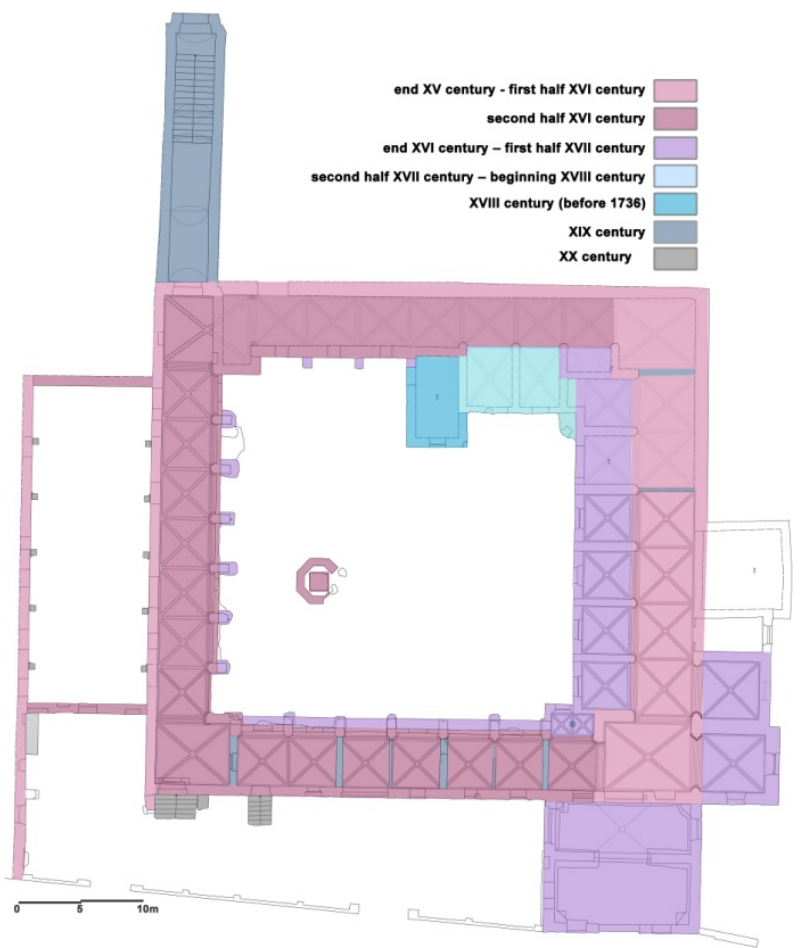

Figure 11: Dating hypothesis of the complex

Reading and reconstructing the historical cartography was also very useful for the definition of a sixth phase, ascribing to the early years of the $19^{\text {th }}$ century, to which the expansions along the southern front of the cloister (no longer existing today, due to the mentioned opening of the new road) can be referred. In the middle $19^{\text {th }}$ century, there were numerous and devastating transformations, from the closing of the arches of the northern southern and western sides of the cloister to the building of closing walls in the spaces on the southern side, also seriously compromised by the opening of a driveway in one of the spans. During the $20^{\text {th }}$ century (seventh phase), and especially after the bombings of 1943, the structures on the second level of the southern and eastern sides collapsed. Furthermore, in consequence to the opening of a new driveway, the height of the floor level of the cloister space was changed with respect to the original one, still visible in the foundations level.

\section{CONCLUSIONS}

The study on the St. Francis cloister represents an example of integration of different disciplines, through which it has been possible to reach a satisfying level of knowledge of a complex architectural building with a high historical and cultural significance. Particularly in those cases where historical documentation is lacking, a direct investigation becomes essential, and its starting point is necessarily a precise and accurate survey.

In this perspective, the laser scanner survey demonstrated all its potential, managing to detect features of fundamental importance for the comprehension of the evolution and consistency of the inspected architectural heritage. In fact, in the presence of stratified structures, marked by irregularities and peculiarities in building, every detail can be a significant clue, which wouldn't be so immediately caught with a traditional survey. Also, these are usually heavily degraded structures, where, as already known, the orthophotos obtained from a laser scanner are the only way for the draw of the building techniques and decorative elements, and of the maps of materials and degradation state. Furthermore, the orthophotos can be used to investigate other dimensional, decorative, stratigraphic, material and pathological elements.

In conclusion, the followed path illustrates that only with a synergy of different cultural backgrounds and specialized expertises it is possible to connect knowledge otherwise confined to specific sectors, and thus unable to reach an exhaustive knowledge. Furthermore, an interdisciplinary approach for the study of cultural heritage is essential in order to plan a proper restoration and conservation intervention, respectful of the formal, material, technological and stylistic aspects that characterize it.

\section{ACKNOWLEDGEMENTS}

The authors thank A. Dessi, R. Busia, V. Pintus and M. Porcu for their help during surveying and drawing.

The Introduction and the Conclusions have been written by all authors. The paragraphs 2 and 5 have been written by C. Giannattasio; the paragraph 3 has been written by G. Vacca; the paragraph 4 has been written by S.M. Grillo.

\section{SELECTED BIBLIOGRAPHY}

References from Book:

AA. VV., 1991. S. Francesco di Stampace, 1861-1991. Quaderno della Soprintendenza ai B.A.A.A.S. per le province di Cagliari e Oristano, n. 4, Cagliari, pp 7-14

Bryan P., Blake B. Bedford J., 2009. Metric Survey Specifications for Cultural Heritage. English Heritage p. 116

Coroneo R., 1993. Architettura romanica dalla metà del Mille al primo '300 in Sardegna. Ilisso, Nuoro, p. 267.

Delogu R., 1953. L'architettura del Medioevo in Sardegna. La Libreria dello Stato, Roma, pp. 212-214.

Pecchioni E., Fratini F., Cantisani E., 2008. Le malte antiche e moderne tra tradizione e innovazione. Patron Editore, p.228.

Siegesmund S., Snethlage R. (editors), 2011. Stone in Architecture Property, Durability. Fourth Edition. Springer Heidelberg Dordrecht, London-New York, p. 552.

\section{References from Other Literature:}

Deidda M., Dessi A., Marras M., Vacca G., 2012. Laser scanner survey to cultural heritage conservation and restoration, in Int. Arch. Photogram. Remote Sens. Spatial Inf. Sci., XXXIX-B5, pp.589-594.

Fiorino D.R., Giannattasio C., Grillo S.M., Vacca G. (2012). Conservation and valorization of historical building: the casestudy of Stampace quarter in Cagliari (Sardinia, Italy). In: Heritage 2012, $3^{\circ}$ International Conference on Heritage and Sustainable Development. vol. III, p. 1777-1786, Barcelos: Green Lines Institute for Sustainable Development, Porto, 1922 June

Kersten Th., Stenberg H., Stiemer E., 2005. Experiences with terrestrial Laser Scanning for indoor cultural heritage applications using two different scanning system. Proc. of the ISPRS WG V/5 "Panoramic Photogrammetry Workshop". Berlin, 24-25/03/2005 IAPRS, v. XXVI, 5/W8 pp.1-6. 